\title{
Corrigendum: A Single Dose of 5-MeO-DMT Stimulates Cell Proliferation, Neuronal Survivability, Morphological and Functional Changes in Adult Mice Ventral Dentate Gyrus
}

\author{
Rafael Vitor Lima da Cruz ${ }^{1 *}$, Thiago C. Moulin ${ }^{2}$, Lyvia Lintzmaier Petiz ${ }^{1}$ and \\ Richardson N. Leão ${ }^{1,3 *}$
}

${ }^{1}$ Neurodynamics Lab, Brain Institute, Federal University of the Rio Grande do Norte, Natal, Brazil, ${ }^{2}$ Institute of Medical Biochemistry, Federal University of Rio de Janeiro, Rio de Janeiro, Brazil, ${ }^{3}$ Developmental Genetics, Department of Neuroscience, Uppsala University, Uppsala, Sweden

Keywords: 5-MeO-DMT, adult neurogenesis, patch clamp, psychedelics, dentate gyrus granule cells

\section{A Corrigendum on}

A Single Dose of 5-MeO-DMT Stimulates Cell Proliferation, Neuronal Survivability, Morphological and Functional Changes in Adult Mice Ventral Dentate Gyrus by Lima da Cruz, R. V., Moulin, T. C., Petiz, L. L., and Leão, R. N. (2018). Front. Mol. Neurosci. 11:312. doi: 10.3389/fnmol.2018.00312

\section{OPEN ACCESS}

Edited and reviewed by: Ashok K. Shetty,

Institute for Regenerative Medicine, Texas A\& M University College of

Medicine, United States

${ }^{*}$ Correspondence: Rafael Vitor Lima da Cruz rafael.lima@neuro.ufrn.br

Richardson N. Leão

richardson.leao@neuro.ufrn.br

Received: 13 December 2018 Accepted: 11 March 2019 Published: 04 April 2019

Citation:

Lima da Cruz RV, Moulin TC, Petiz LL and Leão RN (2019) Corrigendum: A

Single Dose of 5-MeO-DMT

Stimulates Cell Proliferation, Neuronal

Survivability, Morphological and

Functional Changes in Adult Mice Ventral Dentate Gyrus.

Front. Mol. Neurosci. 12:79. doi: 10.3389/fnmol.2019.00079
In the original article, there was an error. We mistakenly stated that 5-MeO-DMT is part of the ayashuasca brew.

A correction has been made to the Introduction, paragraph one:

"Psychoactive tryptamines are a class of molecules that act as a neurotransmitter in the vertebrate brain (Jacob and Presti, 2005). N,N-dimethyltryptamine, (DMT) and analogues, are closely related to 5-methoxy- N,N-dimethyltryptamine (5-MeO-DMT), they can be found in a great variety of plants in South America, with an even greater diversity of chemical analogs (Geyer et al., 2010; Greene, 2013). 5-MeO-DMT is a serotonin agonist that acts in a non-selective manner in 5- $\mathrm{HT}_{2 \mathrm{~A}}$ $>5-\mathrm{HT}_{2 \mathrm{C}}>5-\mathrm{HT}_{1 \mathrm{~A}}$ receptors (Szabo et al., 2014). However, the N-N-DMT has been reported elsewhere to also acts in many glutamate, dopamine, and acethylcholine receptors (Carbonaro and Gatch, 2016). It would be interesting to know whether the 5-MeO-DMT have the same effect as its analogue on those receptors. The 5-MeO-DMT is analogous of the N,N-DMT, one of the main active ingredients of Ayahuasca, a millenarian decoction used as a sacrament by south American indigenous tribes, known to induce powerful hallucinogenic states when administered with monoamine oxidase inhibitors (MAOI; Araújo et al., 2015). At present, Ayahuasca is used by many syncretic churches ritualistically, as a way to heal many physical and mental illnesses with or without scientific knowledge about the effects (Frecska et al., 2016). Recent studies also suggest that Ayahuasca can potentially treat recurrent depression (Osório Fde et al., 2015; Sanches et al., 2016) even in a placebo controlled frame (Palhano-Fontes et al., 2018)."

Additionally, a correction has been made to the Discussion, paragraph three:

"The choice of a single dose treatment, was made to address the gap between the molecular mechanisms, subjective and hormonal effects underlying Ayahuasca acute administration to depression diagnosed patients (dos Santos et al., 2016; Sanches et al., 2016; Galvão et al., 2018; Palhano-Fontes et al., 2018). The bulk of Ayahuasca tea, are composed of several psychoactive 
substances including DMT analogs and MAOi (Frecska et al., 2016; Morales-García et al., 2017). The scope of present study is to unveil the effect of the 5-MeO-DMT, without adding any bias, due to other psychoactive compounds. To study the specific contribution of the 5-MeO-DMT to the adult neurogenic process, we needed to isolate the effect of the 5-MeO-DMT from other psychoactive components. In Ayahuasca tea the DMT is administrated with MAOi, in order to avoid tryptamines degradation. Using oral or intraperitoneal administration without MAOi may reduce the availability of 5$\mathrm{MeO}-\mathrm{DMT}$ to the central nervous system, since the monoamine

\section{REFERENCES}

Araújo, A. M., Carvalho, F., Bastos, M. D. L., Guedes de Pinho, P., and Carvalho, M. (2015). The hallucinogenic world of tryptamines: an updated review. Arch. Toxicol. 89, 1151-1173. doi: 10.1007/s00204-015-1513-x

Carbonaro, T. M., and Gatch, M. B. (2016). Neuropharmacology of N,N-Dimethyltryptamine. Brain Res. Bull. 126, 74-88. doi: 10.1016/j.brainresbull.2016.04.016

dos Santos, R. G., Osório, F. L., Crippa, J. A. S., Riba, J., Zuardi, A. W., and Hallak, J. E. (2016). Antidepressive, anxiolytic and antiaddictive effects of ayahuasca, psilocybin and lysergic acid diethylamide (LSD): a systematic review of clinical trials published in the last 25 years. Ther. Adv. Psychopharmacol. 6, 193-213. doi: $10.1177 / 2045125316638008$

Frecska, E., Bokor, P., and Winkelman, M. (2016). The therapeutic potentials of ayahuasca: possible effects against various diseases of civilization. Front. Pharmacol. 7:35. doi: 10.3389/fphar.2016. 00035

Galvão, A. C. M., de Almeida, R. N., Silva, E. A. D. S., Freire, F. A. M., PalhanoFontes, F., Onias, H., et al. (2018). Cortisol modulation by ayahuasca in patients with treatment resistant depression and healthy controls. Front. Psychiatry 9:185. doi: 10.3389/fpsyt.2018.00185

Geyer, M. A., Nichols, D. E., and Vollenweider, F. X. (2010). "Serotonin-related psychedelic drugs," in Encyclopedia of Neuroscience, ed L. R. Squire (Cambridge, MA: Academic Press), 731-738.

Greene, S. L. (2013). "Chapter 15 Tryptamines: Classification, pharmacology and toxicology," in Novel Psychoactive Substances, eds P. I. Dargan and D. M. Wood (London: Academic Press), 363-381. doi: 10.1016/B978-0-12-415816-0.00015-8

Halberstadt, A. L. (2016). Behavioral and pharmacokinetic interactions between monoamine oxidase inhibitors and the hallucinogen 5-methoxyN,N-dimethyltryptamine. Pharmacol. Biochem. Behav. 143, 1-10. doi: 10.1016/j.pbb.2016.01.005

Halberstadt, A. L., Buell, M. R., Masten, V. L., Risbrough, V. B., and Geyer, M. A. (2008). Modification of the effects of 5-methoxy$\mathrm{N}, \mathrm{N}$-dimethyltryptamine on exploratory behavior in rats by monoamine oxidase will readily destroy any tryptamine, in the bloodstream, guts and also in the brain (Halberstadt et al., 2008; Halberstadt, 2016; Morales-García et al., 2017). Since 5-MeO-DMT can easily be degraded, we chose to deliver the 5-MeO-DMT i.c.v. to reduce the chemical inactivation prior to the arrival of the molecule to the brain. Additionally, it has been reported elsewhere that the harmine per se can increase neurogenesis, at least in vitro cultured hippocampal cells (Morales-García et al., 2017)."

The authors apologize for this error and state that this does not change the scientific conclusions of the article in any way. The original article has been updated. oxidase inhibitors. Psychopharmacology 201, 55-66. doi: 10.1007/s00213-008$1247-\mathrm{z}$

Jacob, M. S., and Presti, D. E. (2005). Endogenous psychoactive tryptamines reconsidered: an anxiolytic role for dimethyltryptamine. Med. Hypotheses 64, 930-937. doi: 10.1016/j.mehy.2004.11.005

Morales-García, J. A., de la Fuente Revenga, M., Alonso-Gil, S., RodríguezFranco, M. I., Feilding, A., Perez-Castillo, A., et al. (2017). The alkaloids of Banisteriopsis caapi, the plant source of the Amazonian hallucinogen Ayahuasca, stimulate adult neurogenesis in vitro. Sci. Rep. 7:5309. doi: 10.1038/s41598-017-05407-9

Osório Fde, L., Sanches, R. F., Macedo, L. R., Santos, R. G., Maia-de-Oliveira, J. P., Wichert-Ana, L., et al. (2015). Antidepressant effects of a single dose of ayahuasca in patients with recurrent depression: a preliminary report. Rev. Bras. Psiquiatr. 37, 13-20. doi: 10.1590/1516-4446-2014-1496

Palhano-Fontes, F., Barreto, D., Onias, H., Andrade, K. C., Novaes, M. M., Pessoa, J. A., et al. (2018). Rapid antidepressant effects of the psychedelic ayahuasca in treatment-resistant depression: a randomized placebo-controlled trial. Psychol. Med. doi: 10.1017/S0033291718001356 [Epub ahead of print].

Sanches, R. F., de Lima Osório, F., Dos Santos, R. G., Macedo, L. R., Maia-deOliveira, J. P., Wichert-Ana, L., et al. (2016). Antidepressant effects of a single dose of ayahuasca in patients with recurrent depression-a SPECT study. J. Clin. Psychopharmacol. 36, 77-81. doi: 10.1097/jcp.0000000000000436

Szabo, A., Kovacs, A., Frecska, E., and Rajnavolgyi, E. (2014). Psychedelic $\mathrm{N}, \mathrm{N}$-dimethyltryptamine and 5-methoxy-N,N-dimethyltryptamine modulate innate and adaptive inflammatory responses through the sigma-1 receptor of human monocyte-derived dendritic cells. PLoS ONE 9:e106533. doi: 10.1371/journal.pone.0106533

Copyright (C) 2019 Lima da Cruz, Moulin, Petiz and Leão. This is an open-access article distributed under the terms of the Creative Commons Attribution License (CC $B Y)$. The use, distribution or reproduction in other forums is permitted, provided the original author(s) and the copyright owner(s) are credited and that the original publication in this journal is cited, in accordance with accepted academic practice. No use, distribution or reproduction is permitted which does not comply with these terms. 